\title{
Synthesis of CdS/ZnS Quantum Dots for Solarcell Applications
}

\author{
Lekshmi Gangadhar \\ Department of Nanotechnology, Noorul Islam Centre for Higher Education, \\ Kumaracoil, Kanya kumari District. \\ Prof. P. K Praseetha \\ Department of Nanotechnology, Noorul Islam Centre for Higher Education, \\ Kumaracoil, Kanya kumari District.
}

\begin{abstract}
Quantum dots are considered as potential candidates for solar cell applications due to quantum confinement effects. An alternative concept to present day photovoltaic devices is the quantum dots-sensitized solar cells (QDSSC). Cadmium sulfide/Zinc sulfide-sensitized solar cells have been synthesized by Chemical bath deposition based on an aqueous medium involving cadmium sulphate, zinc acetate, thiourea and ammonium hydroxide. To improve the luminescence efficiency and photostability of the quantum dots, overcoating quantum dots with another wide band gap semiconductor is a usual procedure. In particular, for CdS quantum dots, the particles were covered with $\mathrm{ZnS}$ to establish a core/shell system. This $\mathrm{CdS} / \mathrm{ZnS}$ quantum dots are assembled onto nanoporous $\mathrm{TiO}_{2}$ films for quantum dotssensitized solar cell applications. The structural and surface morphological properties of nanoparticles were studied using field emission scanning electron microscope (FE-SEM), Transmission electron microscopy (TEM), ultraviolet-visible light (UV-VIS) spectrometer, Fourier transform infrared spectroscopy (FTIR) and X-ray diffraction (XRD). The photovoltaic studies of the cell were carried out and an $\mathrm{I}-\mathrm{V}$ characteristic of the cell was compared with bare $\mathrm{TiO}_{2}$. An efficiency as high as $\mathbf{1 . 8 0} \%$ for the $\mathrm{CdS} / \mathrm{ZnS}$ quantum dots-sensitized solar cells was achieved using the present method.
\end{abstract}

Keywords: cadmium sulfide, zinc sulfide, quantum dots, synthesis, core/shell, solar cells.

\section{INTRODUCTION}

Sulfides are wide-band gap II-VI semiconductor materials, have been studied extensively due to their wide applications in the fields of solarcells, light-emitting devices and optical recording materials. As the physical dimensions of the particle approach to the nanometer scales, quantization and surface effects begin to play an important role, leading to drastic changes in the measured properties [1]. Semiconductor nanoparticles have attracted much attention because of their novel electric and optical properties originating from surface and quantum confinement effects. Due to the quantum size effect, the chemical and physical properties of nanoparticles greatly differ from those of bulk materials. Therefore, much effort has been made to control the size, morphology and polycrystallinity of the nanocrystals with a view to tune their physical properties [18]. Hence, there has been growing interest in developing techniques for preparing semiconductor nanoparticles and films.

The wet chemical synthesis method is a simple and inexpensive alternative to more complex chemical vapor deposition (CVD) and physical techniques. The wet chemical technique offers a simple means to synthesize such particle with good control of size and size distribution. The band gap of particle can be tuned by changing the size of nanocrystals $[9,15]$. Thus there is an increase in the band gap of semiconductor with a decrease in particle size. Moreover, as the particles become smaller a higher surface-to-volume ratio is obtained leading to a rapid increase in surface states, reducing the band gap emission (excitonic emission) via non-radiative recombination in surface traps and affecting the chemical reaction dynamics.

Generally, DSCs consist of a transparent conductive oxide (TCO) electrode coated with mesoporous $\mathrm{TiO}_{2}$ film which sensitized with dyes, a platinum coated counter electrode and an electrolyte containing an iodide/tri-iodide 
redox couple is filled between these two electrodes [4,5,17]. The absorption spectrum of a sensitizer plays an important role in achieving high energy conversion efficiency. The application of the semiconductor quantum dots as the sensitizers has some advantages in sensitized solar cell [6]. The CdS quantum dots particles were covered with $\mathrm{ZnS}$ to establish a core/shell system, where the band gap of the core lies energetically within the band gap of the shell material and the photogenerated electrons and holes are mainly confined inside the CdS [2]. As the $\mathrm{ZnS}$ shell thickness increases, there could be an increased electron-hole pair generation leading to large free-carrier concentration which in turn results in enhancement of nonlinear optical absorption. In addition, it was found that the optical limiting threshold gets decreased as the $\mathrm{ZnS}$ shell thickness increases [3]. The band gap is easily controlled by the size of the quantum dots and thereby the absorption spectrum can be adjustable to match the spectral distribution of sunlight, the band edge type absorption behavior is most favorable for effective light harvesting. The surface properties of the quantum dots can be modified in order to increase the photo stability of the electrodes.

For the assembly of $\mathrm{Q}$ dots, chemical bath deposition (CBD) and the self-assembled monolayer (SAM) methods are usually employed $[12,13]$. CBD is well known as a simple, inexpensive and convenient technique for the deposition of CdS/ZnS. A QDSSC is composed of quantum dots adsorbed nanoporous $\mathrm{TiO}_{2}$ layer on a fluorine-doped tin oxide (FTO) glass substrate, redox electrolytes and a counter electrode $[7,8,10]$. A unidirectional charge flow with no electron leakage at the interfaces is essential for high energy-conversion efficiency. The energy-conversion efficiency is likely to be dependent on the morphology and structure of the quantum dots-adsorbed $\mathrm{TiO}_{2}$ film. $\mathrm{TiO}_{2}$ films are used as photoanodes to enhance the effective surface area, to absorb more quantum dots and thus to achieve more light absorption and greater efficiency [11]. The high conversion efficiency achieved by the QDSSC may be attributed to its uniquely porous titania film, quantum dots and the electrolyte. To improve electron transport, we have to provide a large surface area to adsorb the sensitized quantum dots and enhance incident light harvest $[14,16]$. QDSSCs were constructed by the application of TNWs and $\mathrm{TiO}_{2}$ nanoparticles. TNWs were fabricated by a hydrothermal process. The introduction of TNWs, with a much more open structure, enables the electrolyte to penetrate easily inside the film, increasing the interfacial contact between the nanowires, the quantum dots and the electrolyte. It is expected that the photoelectrical performance of the QDSSC can be further improved.

\section{EXPERIMENTAL DETAILS}

\section{Preparation of CdS/ZnS quantum dots}

The starting materials are Cadmium sulphate as a $\mathrm{Cd}^{++}$ion source and thiourea as an $\mathrm{S}^{--}$ion source. An alkaline solution of ammonia is used to adjust $\mathrm{pH}$ of the reaction mixture. Ammonium hydroxide is added dropwise to cadmium sulphate solution at $50^{\circ} \mathrm{C}$ to adjust $\mathrm{pH}$ to 11 . Thiourea is added dropwise to this which results in yellow colour precipitate of CdS quantum dots. Zinc acetate solution is added to this followed by addition of Ammonium hydroxide. Thiourea is added dropwise to this results in precipitate of $\mathrm{CdS} / \mathrm{ZnS}$ quantum dots. Filter the precipitate and wash several times with double distilled water and dried in oven at $70^{\circ} \mathrm{C}$ to collect nanopowders . This results in the formation of $\mathrm{CdS} / \mathrm{ZnS}$ quantum dots.

\section{Preparation of $C d S / Z n S$ quantum dots using leaf extract}

Moringa oleifera leaves contains sulfur-containing amino acids in higher levels. Moringa oleifera extract was prepared by taking $20 \mathrm{~g}$ of dry Moringa oleifera leaves, thoroughly washed and finely crushed mixed with $50 \mathrm{ml}$ of deionized water and boiling the mixture at $80^{\circ} \mathrm{C}$ for $15 \mathrm{~min}$. Cool to room temperature and the extract was filtered by Whatmann filter paper. The $\mathrm{Cd}^{++}$ion source is Cadmium sulphate and $\mathrm{S}^{--}$ion source is moringa oleifera extract. An alkaline solution of ammonia is used to adjust $\mathrm{pH}$ of the reaction mixture. Ammonium hydroxide is added dropwise to cadmium sulphate solution at $50^{\circ} \mathrm{C}$ to adjust $\mathrm{pH}$ to 11 . Moringa oleifera leaf extract is added dropwise to this which results in yellow colour precipitate of CdS quantum dots. Zinc acetate solution is added to this followed by addition of Ammonium hydroxide. Moringa oleifera leaf extract is added dropwise to this results in precipitate of $\mathrm{CdS} / \mathrm{ZnS}$ quantum dots. Filter the precipitate and wash several times with double distilled water and dried in oven at $70^{\circ} \mathrm{C}$ to collect nanopowders . This results in the formation of $\mathrm{CdS} / \mathrm{ZnS}$ quantum dots.

\section{Preparation of $\mathrm{TiO} 2$ nanowires}

Take 0.1 gram of anatase $\mathrm{TiO}_{2}$ (Aldrich Chemical, Sigma-Aldrich Corporation, St. Louis, MO, USA) and $40 \mathrm{ml}$ of 10 $\mathrm{M} \mathrm{NaOH}$, heated under stirring at $100^{\circ} \mathrm{C}$ for 5 hours. The mixture is kept in oven at $200^{\circ} \mathrm{C}$ for 24 hours. The resultant sample is filtered. The filtrate was taken and $1 \mathrm{M} \mathrm{HCl}$ was added dropwise under stirring until the $\mathrm{pH}$ 
became 7. The precipitate formed is filtered, washed sequentially with double distilled water and ethanol for several times. The sample is dried in hot air oven at $70^{\circ} \mathrm{C}$ for 8 hours. A fibrous white product was obtained.

\section{Preparation of TiO2 electrode films}

An optically transparent conducting glass (FTO, sheet resistance $8 \Omega / \mathrm{sq}$ ) was washed in ethanol and deionized water in an ultrasonic bath for 10 minutes. The FTO glass was immersed in $\mathrm{TiCl}_{4}$ aqueous solution at $70^{\circ} \mathrm{C}$ for 30 minutes to make good mechanical contact. $\mathrm{A} \mathrm{TiO}_{2}$ film with a thickness of 12 to $15 \mu \mathrm{m}$ was deposited onto the pretreated conducting glass using the doctor blading technique and sintered again at $450^{\circ} \mathrm{C}$ for 15 minutes and at $500^{\circ} \mathrm{C}$ for 15 minutes. In doctor blading method, a small rectangle was tapped off so that it covers the majority of one half the electrode. Then a few drops of the titanium dioxide nanowires was placed in the non-tapped area and a glass slide was used to smooth out the titanium dioxide nanowires until it appeared to be uniform over the entire exposed surface. The layer coated should be of uniform thickness. Once coated by any of the above mentioned technique, they are dried at $60{ }^{\circ} \mathrm{C}$ and those dried layers are sintered at high temperatures $\left(500^{\circ} \mathrm{C}\right)$ to remove any organic components in $\mathrm{TiO}_{2}$ and also to improve the mechanical contact of the particles. This sintering process has a great impact on the films. If the electrodes were stored, they were again heated to $450^{\circ} \mathrm{C}$ for 30 minutes prior to sensitization because it was found that the quality of the $\mathrm{TiO}_{2}$ film worsen with time due to the adsorption of pollutants $\left(\mathrm{CO}_{2}\right.$, dust) from the gas phase.

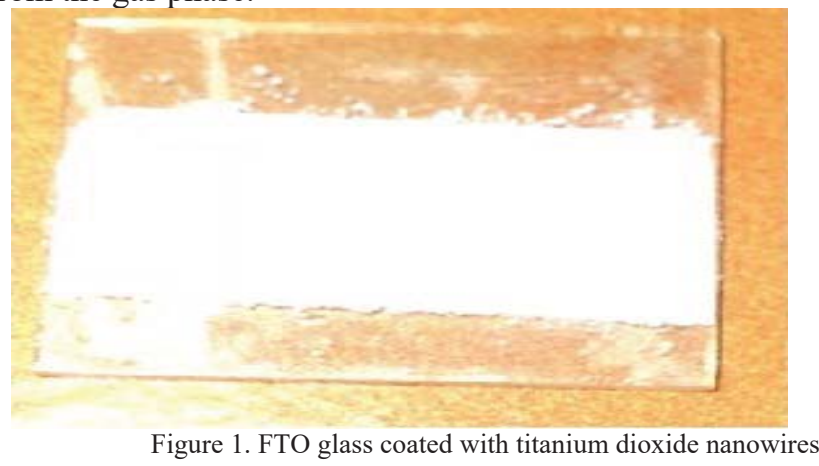

\section{Preparation of Electrolyte Solution}

For the application of quantum dot sensitized solar cell, potassium iodide electrolyte was developed. A solvent consisting of potassium iodide and ethylene glycol is prepared and stored in a dark container

\section{Assembly of the QDSSCs}

The working electrode used was $\mathrm{TiO}_{2}$ coated FTO, sensitized with $\mathrm{CdS} / \mathrm{ZnS}$ quantum dots. The counter electrode was graphite FTO glass. The cell was fabricated with great care in sandwich form by clamping working electrode and counter electrode, so as to take leads from both the electrodes. An effective working area of $0.25 \mathrm{~cm}^{2}$ was exposed to light source, while all other areas were masked. For the application of quantum dot sensitized solar cell, potassium iodide electrolyte was developed. A solvent consisting of potassium iodide and ethylene glycol is prepared and stored in a dark container. Prior to clamping, one or two drops of electrolyte freshly prepared were placed above the working electrode. It should be ensured that the whole aperture was covered by the electrolyte and the electrodes were tightly held with the help of crocodile clip.

\section{Measurements}

The morphologies and thickness of $\mathrm{TiO}_{2}$ nanowires and $\mathrm{CdS} / \mathrm{ZnS}$ quantum dots were characterized by field emission scanning electron microscopy (FE-SEM, Hitachi-S4700) and X-ray diffractometer (XRD, D/max 2200, Rigaku) with $\mathrm{Cu}$ Ka irradiation. The optical property was characterized by an ultraviolet-visible light (UV-VIS) spectrometer (Hitachi, U-3010). Photocurrent- voltage (I-V) characteristics of the quantum dot sensitized solar cells were measured using a Keithley electrometer under illumination and non-illumination conditions by using the sun simulator Oriel Sol 3A which includes a Xenon lamp at an intensity of $100 \mathrm{~mW} / \mathrm{cm}^{2}$ (AM1.5). The active area of the resulting cell exposed to light was approximately $0.25 \mathrm{~cm}^{2}(0.5 \mathrm{~cm} \times 0.5 \mathrm{~cm})$.

\section{RESULTS AND DISCUSSIONS}




\section{SEM observations of $\mathrm{TiO}_{2}$ nanowires and $\mathrm{CdS} / \mathrm{ZnS}$ quantum dots}

SEM pictures revealed that $\mathrm{CdS} / \mathrm{ZnS}$ quantum dots and $\mathrm{TiO}_{2}$ nanowires successfully prepared. SEM pictures shows needle like self-assembled one-dimensional nanostructures which may be regarded as $\mathrm{TiO}_{2}$ nanowires. Figure 2. (a) revealed a high yield of nanowires. The average length of the wires was about 2-4 $\mu \mathrm{m}$ and the average diameter was 40-50 nm. Spherical like structures were observed in CdS/ZnS QDs prepared in chemical bath deposition (CBD) method, figure 2. (b) and (c). The crystalline natures of the observed particles are very good. The average diameter of the $\mathrm{CdS} / \mathrm{ZnS}$ quantum dots by chemical synthesis was about 6-8 $\mathrm{nm}$ and the average diameter of CdS/ZnS quantum dots by green synthesis was 7-9 $\mathrm{nm}$.

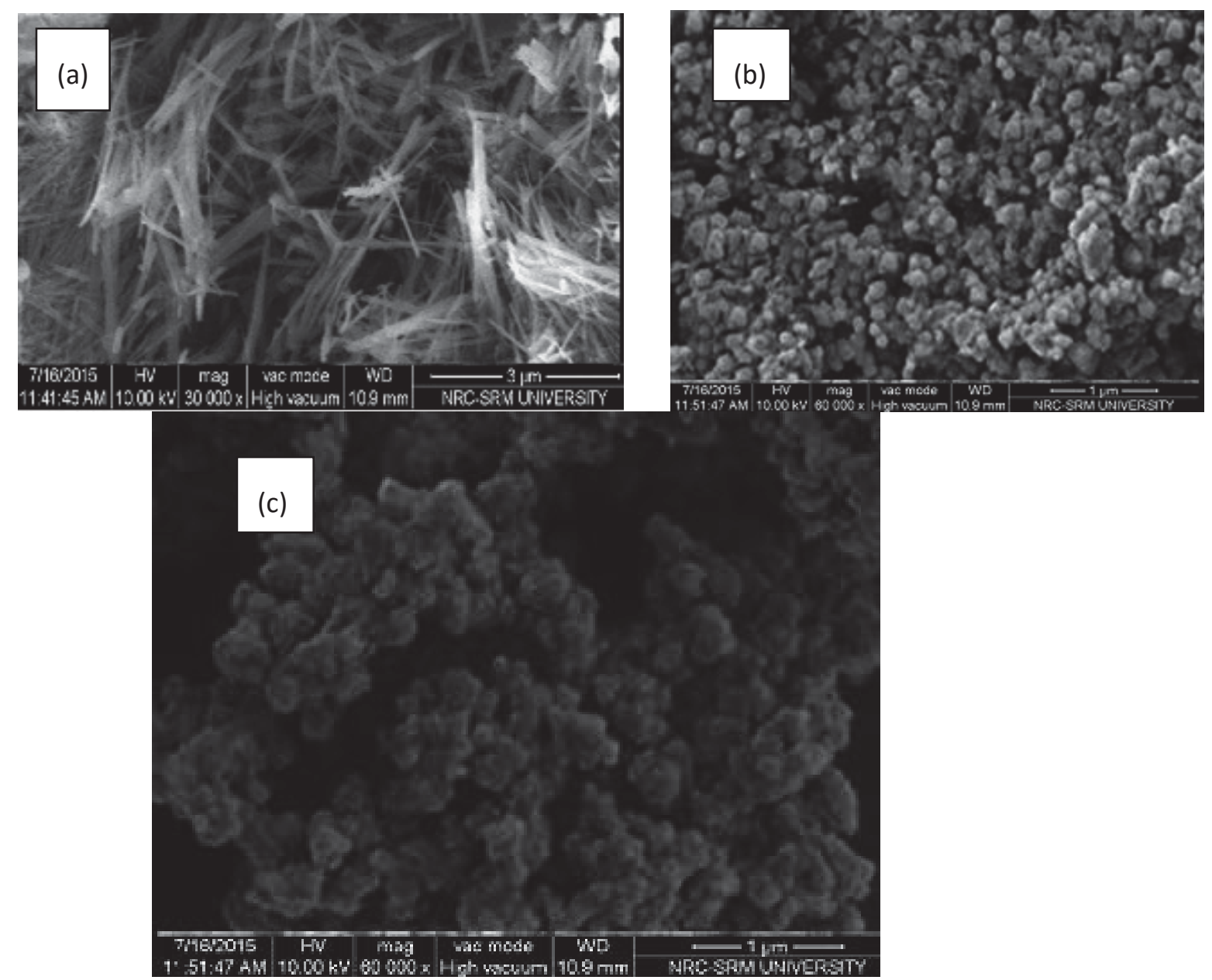

Figure 2. SEM images of (a) TiO2 nanowires, (b) CdS/ZnS quantum dots by chemical method, (c) CdS/ZnS quantum dots by green method

\section{TEM observations of CdS/ZnS quantum dots}

Transmission electron microscopy has been performed to ensure about the particle size and the result have been presented in figure 3. TEM image of CdS/ZnS QDs show highly monodispersed nanoparticles with average sizes of 3-7 nm. It is also clear from the figure that there is no agglomeration of QDs. The particle size obtained from TEM is highly in accordance with the size obtained from XRD analysis. 

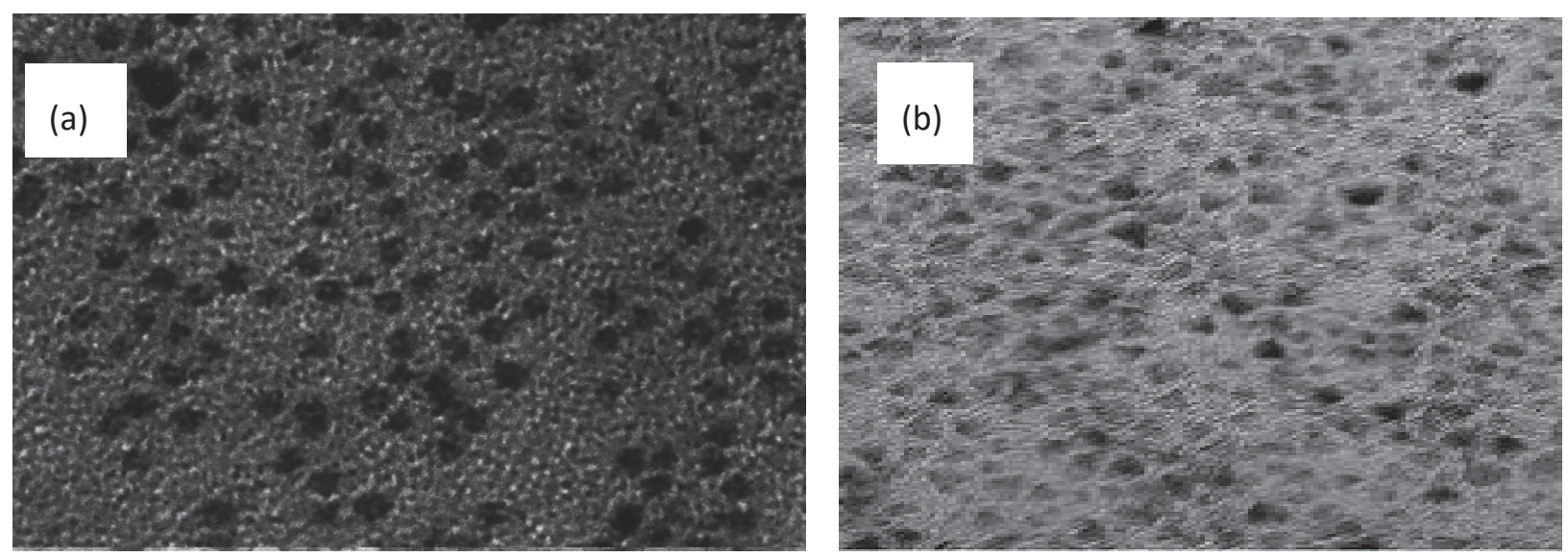

Figure 3. TEM images of (a) CdS/ZnS quantum dots by chemical method, (b) $\mathrm{CdS} / \mathrm{ZnS}$ quantum dots by green method

\section{XRD observations of TiO2 nanowires and CdS/ZnS quantum dots}

The X-ray diffraction (XRD) pattern of $\mathrm{TiO}_{2}$ Nanowire is shown in figure 4. (a). In Case of $\mathrm{TiO}_{2}$ nanowires, the prominent peaks of $\mathrm{d}=0.325$ and $\mathrm{d}=0.1628$ indicates good crystallinity of the $\mathrm{TiO}_{2}$ anatase phase. Figure 4. (b) shows the XRD pattern of the CdS/ZnS QDs deposited by the chemical bath deposition (CBD) method. The most prominent peaks are similar as ZnS QDs i.e (002) direction along with the other reflections at (200) and (201) planes. These peaks show that $\mathrm{ZnS}$ is present at the outer surface in the form of a shell. The average particle size of $\mathrm{CdS} / \mathrm{ZnS}$ core shell was measured using Debye Scherrer formula and was found around $4.2 \mathrm{~nm}$. According to XRD both $\mathrm{CdS}$ and $\mathrm{ZnS}$ peaks were present in the core shell structure so that core shell structure. The presence of high intensity peaks $\left(2 \theta=27.58^{\circ}\right)$ clearly shows that the particle size of $\mathrm{CdS} / \mathrm{ZnS}$ is very small corresponding to the (002) plane for $\mathrm{CdS} / \mathrm{ZnS}$ quantum dots by Chemical method. The presence of peaks at $2 \theta=25.85^{\circ}, 42.82^{\circ}, 47.81^{\circ}$ shows that the particle size of $\mathrm{CdS} / \mathrm{ZnS}$ is very small and it was found to be around $4.6 \mathrm{~nm}$ corresponding to the $\mathrm{CdS} / \mathrm{ZnS}$ quantum dots by green method in figure 4 . (c).

The particle size was calculated by using Scherrer's formula

$$
\mathrm{D}=\mathrm{K} \lambda / \beta \cos \theta
$$

where $\mathrm{K}$ is the shape factor (0.9), $\beta$ is the full width at half maximum (FWHM), $\lambda$ is the wavelength of $\mathrm{CuK} \alpha 1$ radiation (1.5406 $\AA$ ), $\theta$ is the Bragg's diffraction angle.

(a)

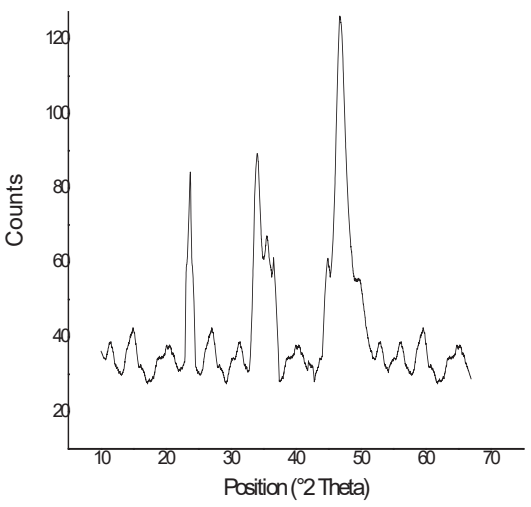

(b)

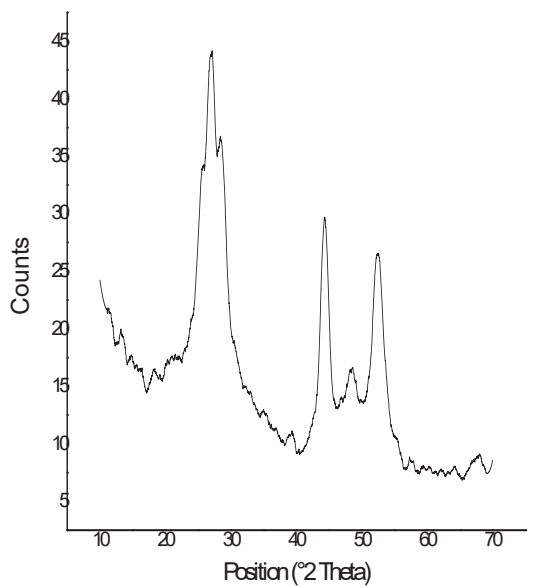


(c)

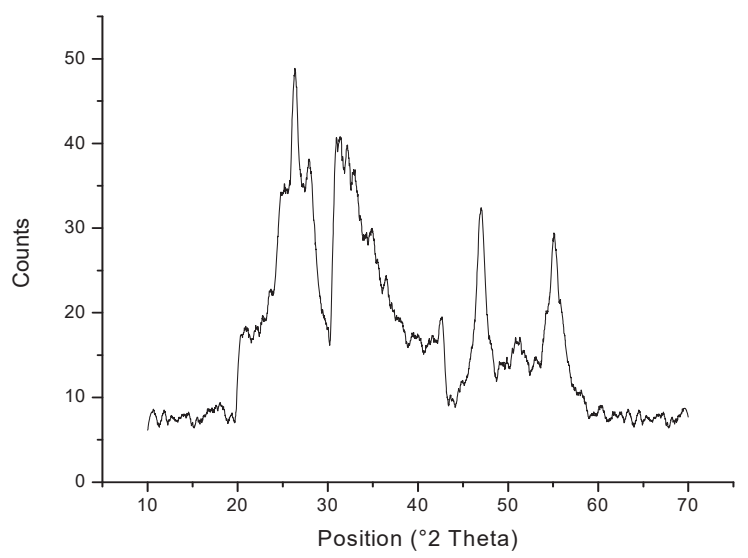

Figure 4. XRD images of (a) TiO2 nanowires, (b) CdS/ZnS quantum dots by chemical method, (c) CdS/ZnS quantum dots by green method

\section{UV-Visible Spectroscopy of TiO2 nanowires and CdS quantum dots}

The optical absorption spectrum of $\mathrm{TiO}_{2}$ nanowires and $\mathrm{CdS} / \mathrm{ZnS}$ quantum dots is shown in figure 5. (a) and (b). In the absorption spectrum obtained, the peak at $252 \mathrm{~nm}$ indicates the absorption due to anatase $\mathrm{TiO}_{2}$. From the spectrum the optical absorption excitonic peak of $\mathrm{CdS} / \mathrm{ZnS}$ quantum dots is shifted to the lower wavelength side relative to that of bulk $(\sim 530 \mathrm{~nm})$ crystals. This continuous blue shift shows that quantum confinement occurred in the prepared quantum dots. The absorption edge of the core/shell structure is lies between $\mathrm{CdS}$ and $\mathrm{ZnS}$ quantum dots because surface to volume ratio in core/shell is more than $\mathrm{CdS}$ but less than $\mathrm{ZnS}$. In semiconductors, the relation connecting the absorption coefficient $\alpha$, the incident photon energy hv and optical band gap Eg takes the form

$$
\alpha \mathrm{h} v=\mathrm{k}(\mathrm{h} v-\mathrm{Eg}) \mathrm{m}
$$

where $\mathrm{k}$ is a constant related to the effective masses associated with the bands and $\mathrm{m}=1 / 2$ for a direct-gap material, 2 for an indirect-gap material and 3/2 for a forbidden-direct energy gap.

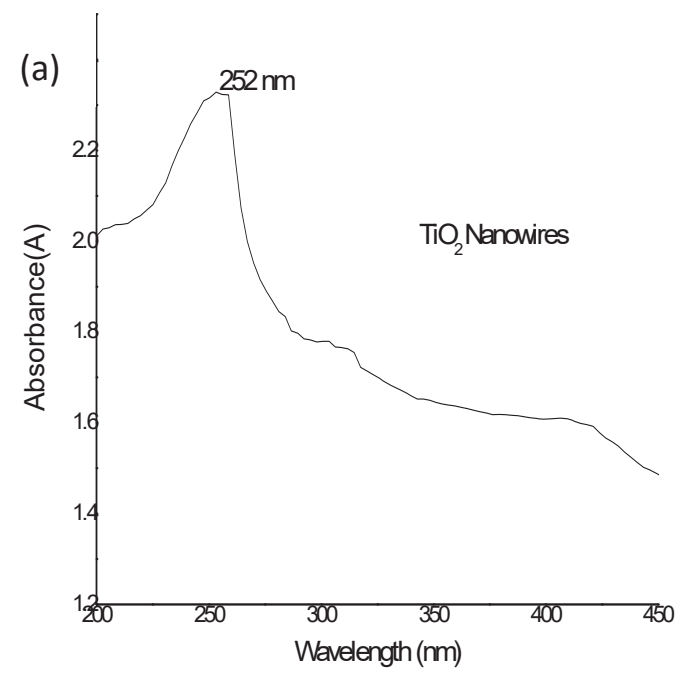

(b)
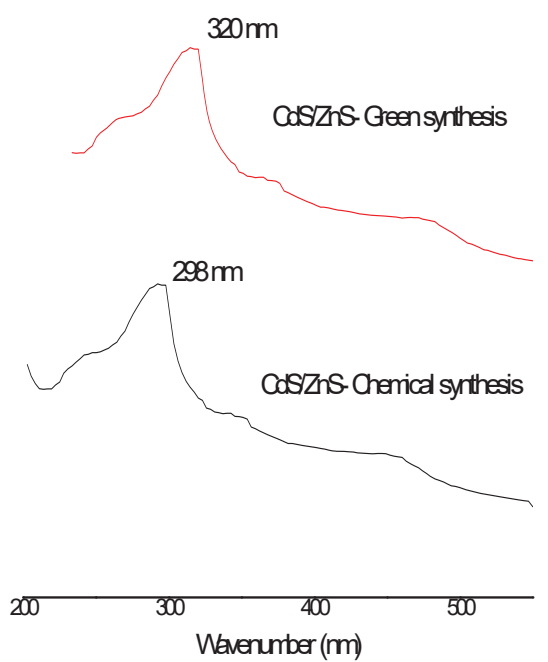

Figure 5. UV-Visible images of (a) $\mathrm{TiO} 2$ nanowires, (b) $\mathrm{CdS} / \mathrm{ZnS}$ quantum dots by chemical method and $\mathrm{CdS} / \mathrm{ZnS}$ quantum dots by green method

5. FTIR of TiO2 nanowires and CdS/ZnS quantum dots 
The relative IR absorbance significantly depends on short range environment of oxygen coordination around cations in the lattice, crystal geometry and oxidation state of its cations. A typical IR spectrum of the sample was recorded on a $\mathrm{NaCl}$ crystal which is shown in figure $6 . \mathrm{TiO}_{2}$ - anatase form nanowires having characteristic peaks at 638,513 and $397 \mathrm{~cm}^{-1}$ were observed in the FTIR spectrum, figure 6. (a). An initiation of the prominent peak from $404 \mathrm{~cm}^{-1}$ is a specifically characteristic of $\mathrm{TiO}_{2}$ - anatase. In figure 6. (b) and (c), a broad absorption band around $3400 \mathrm{~cm}^{-1}$ is assigned to $\mathrm{O}-\mathrm{H}$ vibration of absorbed $\mathrm{H}_{2} \mathrm{O}$. The absorption band present at $644 \mathrm{~cm}^{-1}$ corresponds to Cd-S stretching. The band around $1500 \mathrm{~cm}^{-1}$ is due to $\mathrm{NH}_{2}$ bending. The band near $2353 \mathrm{~cm}^{-1}$ can be attributed to $\mathrm{C}=\mathrm{O}$ residue probably due to atmospheric $\mathrm{CO}_{2}$. These results shows how effectively $\mathrm{ZnS}$ covers the $\mathrm{CdS}$ core.

(a)

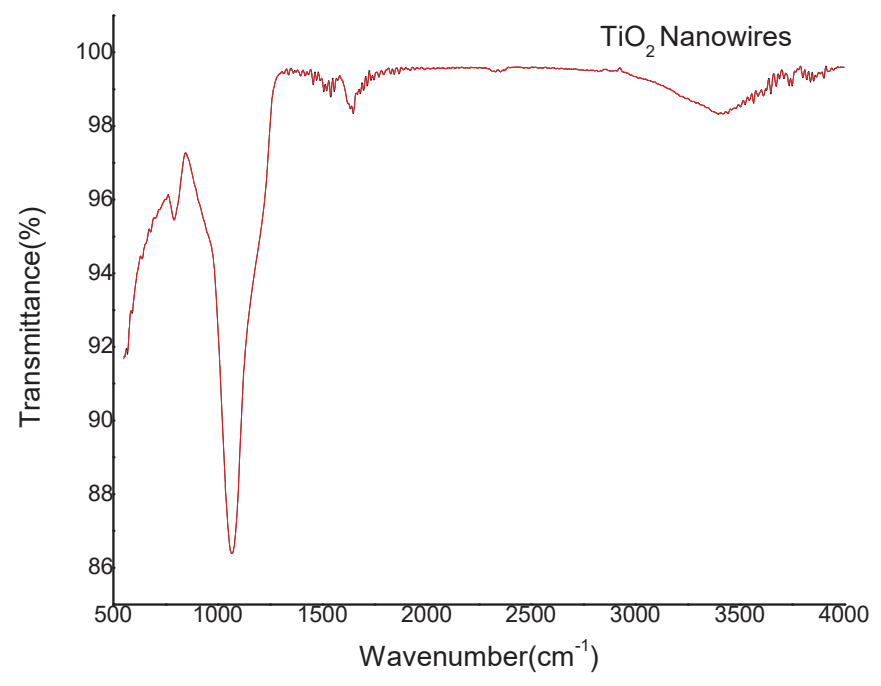

(b)

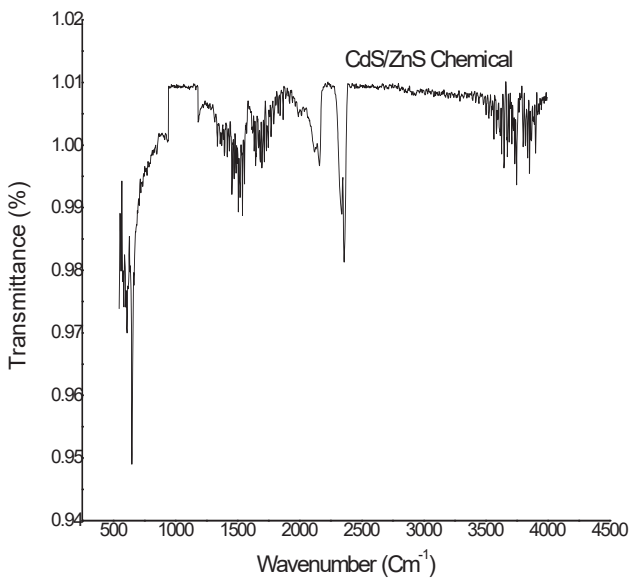

(c)

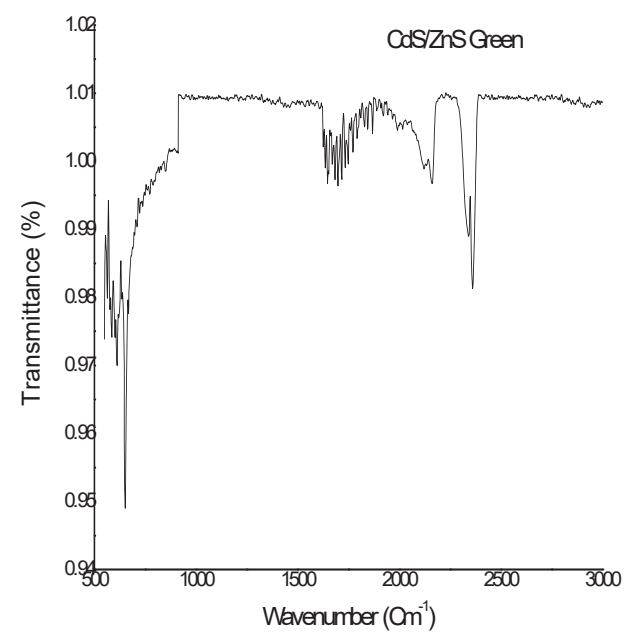

Figure 6. FTIR spectra of (a) TiO2 nanowires, (b) CdS/ZnS quantum dots by chemical method (c) CdS/ZnS quantum dots by green method

6. Photocurrent- voltage (I-V) characteristics DSSCs 
The I-V characteristics of quantum dot sensitized solar cell $\left(\mathrm{FTO} / \mathrm{TiO}_{2} / \mathrm{CdS} / \mathrm{ZnS}\right.$ QDs/Graphite/FTO) were measured using a solar simulator and the results are shown in figure 7, figure 8 and figure 9 . The photocurrent is defined as the current produced under light irradiation due to generation of free charge carriers by absorption of photons within the depletion layer. The efficiency of solarcell under illumination and non-illumination conditions (with light (wl) and without light (wol)) is also calculated.

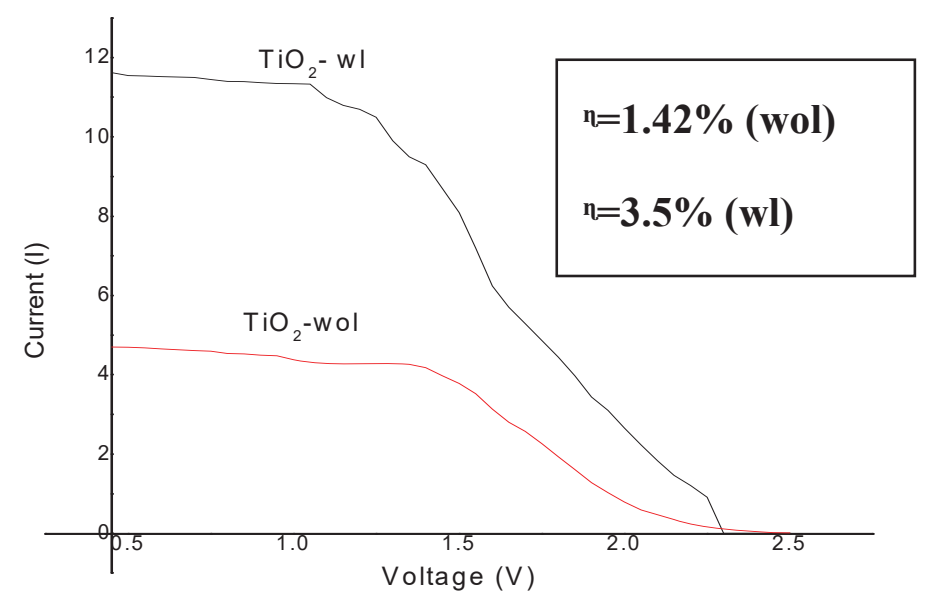

Figure 7. I-V characteristics of $\mathrm{TiO} 2$ nanowires with light (wl) and without light (wol)

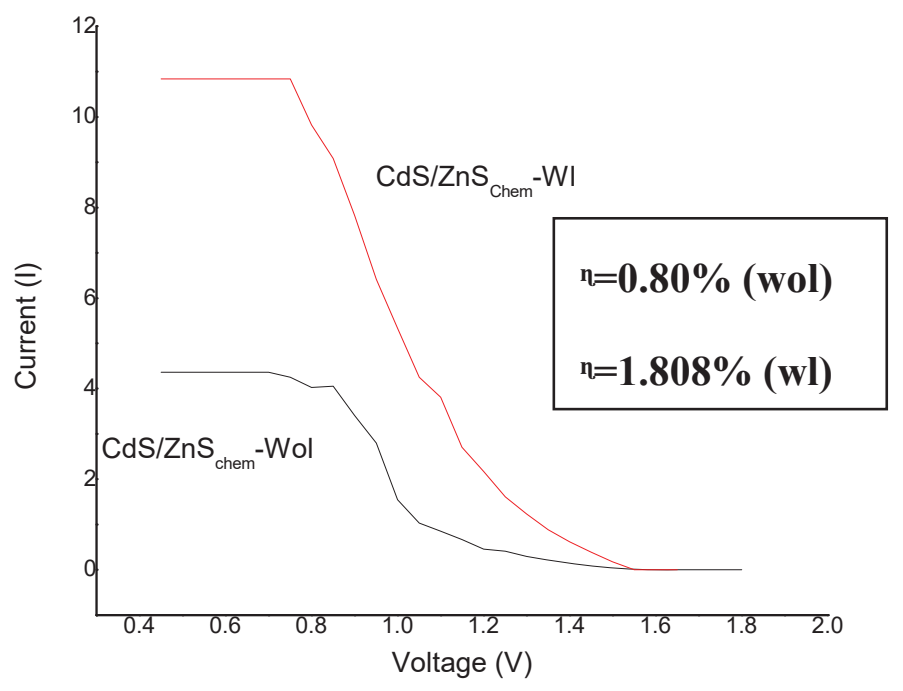

Figure 8. I-V characteristics of CdS/ZnS quantum dot solarcell by chemical method with light (wl) and without light (wol) 


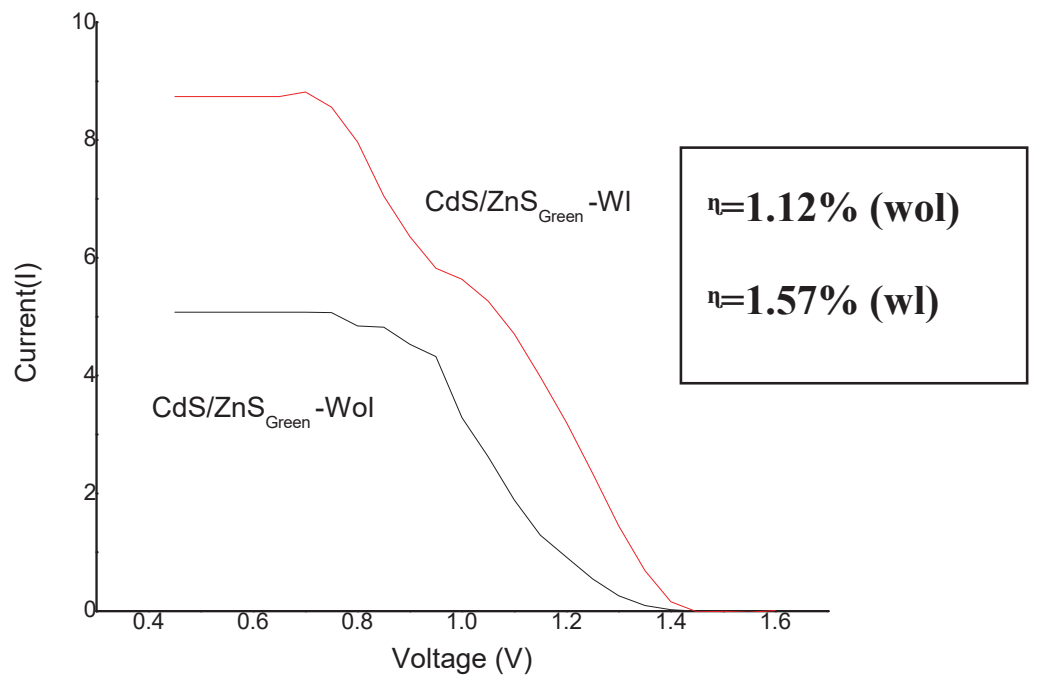

Figure 9. I-V characteristics of CdS/ZnS quantum dot solar cell by green method with light (wl) and without light (wol)

\section{CONCLUSIONS}

$\mathrm{CdS} / \mathrm{ZnS}$ their core shell structure were successfully synthesized through aqueous chemical route and their structural as well as optical properties were investigated by XRD, UV-Vis Spectroscopy, FTIR, SEM and TEM. XRD results indicated that lower synthesis temperature resulted in lower grain size and the particle sizes of $\mathrm{CdS} / \mathrm{ZnS}$ quantum dots as determined from XRD and TEM image are in good agreement. The UV-Visible spectra show a large blue shift attributing the enhanced optical properties this size dependent blue shift of absorption edge is attributed to the quantum size effect. Core/shell semiconductor nanocrystals that were prepared by this method are low-cost, safe and environmental friendly. The crystallization quality of the $\mathrm{CdS} / \mathrm{ZnS}$ quantum dots was improved after the annealing process. A broad enhancement range from $250 \mathrm{~nm}$ to $350 \mathrm{~nm}$ in the absorption spectrum was observed. The overall energy conversion efficiency of the formed cells was $1.80 \%$. The results have demonstrated the potential applications of chemical bath deposited CdS/ZnS quantum dots for sensitized solar cells. This method can also be applicable to synthesize the other core/shell semiconductor nanocrystals. It is expected that the conversion efficiency can be further improved by optimizing the thickness of the $\mathrm{TiO}_{2}$ electrode.

\section{REFERENCES}

[1] Biswas S., Hossain M .F., Takahashic T. "Fabrication of Grätzel solar cell with $\mathrm{TiO}_{2} / \mathrm{CdS}$ bilayered photoelectrode". Thin Solid Films, vol.5, 2008, pp.1284-1288.

[2] Dethlefsen Johannes. R., Anders Dossing. "Preparation of a ZnS Shell on CdSe Quantum Dots Using a Single-Molecular ZnS Precursor". Nano Letters, vol.11, 2011, pp.1964-1969.

[3] Grabolle Markus., Jan Ziegler., Alexei Merkulov., Thomas Nann., Ute Resch-Genger. "Stability and fluorescence quantum yield of CdSe$\mathrm{ZnS}$ quantum dots-influence of the thickness of the ZnS shell". Annals of the New York Academy of Sciences, vol.11, 2008, pp.235-241.

[4] Grätzel M. "Solar energy conversion by dye-sensitized photovoltaic cells" Inorg. Chem., vol.44, 2005, pp.6841-6851.

[5] Guo W.X., Xu C., Wang X., Wang S.H., Pan C.F., Lin C.J., Wang Z.L.” Rectangular bunched rutile $\mathrm{TiO}_{2}$ nanorod arrays grown on carbon fiber for dye-sensitized solar cells". J. Am. Chem. Soc., vol.134, 2012, pp.4437-4441.

[6] Kong E.H., Chang Y.J., Park Y.C., Yoon Y.H., Park H.J., Jang H.M.” Sea urchin $\mathrm{TiO}_{2}$-nanoparticle hybrid composite photo electrodes for CdS/CdSe/ZnS quantum-dot-sensitized solar cells". Phys. Chem., vol.14, 2012, pp.4620-4625.

[7] Liao J.Y., Lei B.X., Chen H.Y., Kuang D.B., Su C.Y." Oriented hierarchical single crystalline anatase $\mathrm{TiO}_{2}$ nanowire arrays on Ti-foil substrate for efficient flexible dye-sensitized solar cells". Energy Environ. Sci., vol.5, 2012, pp.5750-5757.

[8] Liao J.Y., Lei B.X., Kuang D.B., Su C.Y. "Tri-functional hierarchical $\mathrm{TiO}_{2}$ spheres consisting of anatase nanorods and nanoparticles for high efficiency dye-sensitized solar cells". Energy Environ. Sci., vol.4, 2011, pp.4079-4085.

[9] Michele P., Sven R., Adam G., David A.K., Hannah N.B., Paolo M.S., Daniela N., Rodrigo M., Assaf Y.A., Arie Z., et al." ${ }^{\text {TiO }} 2 / \mathrm{Cu}_{2} \mathrm{O}$ alloxide heterojunction solar cells produced by spray Pyrolysis". Sol. Energy Mater. Sol. Cells, vol.132, 2015, pp.549-556. 
[10] Sheng-Qiang Fan., Duckhyun Kim., Jeum-Jong Kim., Dong Woon Jung., Sang Ook Kang., Jaejung Ko. "Highly efficient CdSe quantumdot-sensitized $\mathrm{TiO}_{2}$ photoelectrodes for solar cell applications". Electrochem. Commun., vol.11, 2009, pp.1337-1339.

[11] Sogabe T., Shoji Y., Ohba M., Yoshida K., Tamaki R., Hong H.F., Wu C.H., Kuo C.T., Tomic S., Okada Y., et al. "Intermediate band dynamic of quantum dots solar cell in concentrated photovoltaic modules" Sci. Rep., vol.4, 2014, doi:10.1038/srep04792.

[12] Song. H.K, Yoon. J.S, Won. J, Kim. H, Yeom. M.S," New approach to the reduction of recombination in dye-sensitized solar cells via complexation of oxidized species", J. Nanosci. Nanotechnology., vol.13, pp. 5136-5141, 2013.

[13] Sun X.M., Sun Q., Li Y., Sui L.N., Dong L.F. ” Effects of calcination treatment on the morphology and crystallinity and photoelectric properties of all-solid-state dye-sensitized solar cells assembled by $\mathrm{TiO}_{2}$ nanorod arrays". Phys. Chem. Chem. Phys., vol.15, 2013, pp.18716-18720.

[14] Tahmbidura. M., Muthukumarasamy M., Dhyalan Velauthapillai., Agila. S., Balasundaraprabu R. "Structural, optical and electrical properties of cobalt-doped CdS quantum dots". Electronic Materials, vol.41, 2012, pp.665-672.

[15] Tan X., Qiang P., Zhang D., Cai X., Tan S., Liu P., Mai W .” Three-level hierarchical $\mathrm{TiO}_{2}$ nanostructure based high efficiency dyesensitized solar cells". Crys Eng Comm, vol.16,2014, pp.1020-1025.

[16] Thambidurai M., Muthukumarasamy N., Agilan S., Murugan N., Vasantha S., Balasundaraprabhu R., Senthil T. S. "Strong quantum confinement effect in nanocrystalline CdS" J Mater Sci, vol.45, 2013, pp.3254-3258.

[17] Wu Q., Wu B. X. L., Hua S.R., Cheng Y.S., Dai B.K.” Hydrothermal fabrication of hierarchically anatase $\mathrm{TiO}_{2}$ nanowire arrays on FTO glass for dye-sensitized solar cells". Sci. Rep., vol.3, 2013, doi:10.1038/srep01352.

[18] Xu X.B., Huang S.Y., Chu J.B., Zhu H.B., Sun Z., Chen Y.W., Huang S.M. "Influence of cadmium salts on a modified chemical bath deposition of cadmium sulfide thin films”. Surf. Rev. Lett., vol.15, 2008, pp. 265-270. 